\title{
Platelet-rich plasma or blood-derived products to improve endometrial receptivity?
}

\author{
Adriana Bos-Mikich $^{1}$ (D) $\cdot$ Marcelo O. Ferreira ${ }^{2} \cdot$ Ricardo de Oliveira $^{3} \cdot$ Nilo Frantz $^{2}$
}

Received: 21 August 2018 / Accepted: 14 December 2018 / Published online: 4 January 2019

(C) Springer Science+Business Media, LLC, part of Springer Nature 2019

\begin{abstract}
The use of platelet-rich plasma (PRP) to improve endometrial receptivity is gaining increasing attention in assisted reproduction technologies. The authors report that autologous PRP intrauterine administration improves pregnancy and birth rates, particularly in cases of patients presenting poor endometrial growth. Different groups of scientists proposed a similar approach years ago using whole blood-derived products also to improve endometrial receptivity. The important role played by cytokines and growth factors during embryo implantation has been well-known for a long time. These signaling molecules are present and released by blood cells during physiological, normal endometrial growth and implantation. Similar blood mediators are released from platelet granules upon a blood vessel injury. Methods described for PRP preparation for intrauterine administration are not precise, and they seem to be similar to those used to prepare peripheral blood-derived products. Thus, it is possible that when preparing PRP from whole blood, the final plasma product used as "PRP" contains platelets in addition to the important cytokines and growth factors released by the peripheral blood mononuclear cells present in the whole blood. Precise knowledge of the identity, concentration, and effects of the individual blood factors, their origin, whether platelets or blood mononuclear cells, will greatly contribute to improve and to make results obtained in fertility treatments more repeatable.
\end{abstract}

\section{Introduction}

The important role played by the endometrium for establishing and maintaining a normal pregnancy is beyond doubt. In natural menstrual cycles, the human endometrium becomes receptive to implantation approximately six days postovulation when the embryo reaches the blastocyst stage. A complex series of interactions between the blastocyst and the endometrium takes place, leading to the attachment of the embryo to the luminal epithelium and subsequent invasion into the stroma to establish a relationship with maternal vasculature [1].

It is clear from the literature that implantation depends on a coordinated crosstalk between intrauterine factors and the

Adriana Bos-Mikich

adriana.bosmikich@gmail.com

1 Department of Morphological Sciences, Federal University of Rio Grande do Sul, Porto Alegre, Brazil

2 nilo.frantz Medicina Reprodutiva, Porto Alegre, RS, Brazil

3 RDO, Medical Diagnosis, São Paulo, Brazil embryo itself. The major regulatory role played by ovarian steroids, progesterone, and estrogen on implantation is wellknown. These hormones mobilize different molecular modulators in a spatiotemporal manner, which supports embryo implantation [2]. Endometrial epithelium, decidualized stromal cells, and immune cells produce and secrete paracrine signaling molecules known as growth factors and cytokines. Their action promotes decidual reaction, blastocyst attachment, and invasion [3, 4]. Despite all the knowledge accumulated on the factors involved in normal implantation, very little is known about the silent, undetectable factors in the uterine microenvironment that may also affect the process, representing key components on a successful and full-term gestation.

In Assisted Reproductive Technology (ART) cycles, implantation failure is an important limiting factor. It has been acknowledged for a long time that inadequate endometrial receptivity is one important cause of failures in ART cycles.

Ultrasound evaluation of the uterine cavity is a common practice during ART cycles to define a receptive endometrium based on its thickness and echogenicity. It is generally agreed that a hypoechogenic endometrium [5] with a thickness of $\geq$ $7 \mathrm{~mm}$ on the day human chorionic gonadotropin (hCG) corresponds to a receptive endometrium. However, successful 
pregnancies have been reported in thin $(<4 \mathrm{~mm})[6]$ and hyperechogenic endometrium [7].

Another common unsuspected intrauterine condition that may interfere with the implantation process is chronic endometritis (CE). It is known for some time that $30.3 \%$ of patients with repeated implantation failure following In Vitro Fertilization (IVF) cycles present $\mathrm{CE}$ and women diagnosed with CE had lower implantation rates $(11.5 \%)$ after an IVF cycle [8]. Not surprisingly, in patients complaining of recurrent implantation failure, antibiotic treatment significantly improved the reproductive outcome at a subsequent IVF cycle [9].

Maternal immunological tolerance towards the embryo represents an additional relevant factor required for successful implantation in a secretory endometrium. It is not fully understood, however, how the local immune tolerance happens. The lack of knowledge of the molecular mechanisms underlying the phenomenon of immunological tolerance that occurs during implantation may be one of the reasons why this topic does not receive the same attention as other infertility factors. Several signaling molecules involved in the immune response taking place during embryo implantation are produced and released by blood born white cells and platelets or are present in the plasma and interstitial fluids.

This article provides a review on the roles of known growth factors and cytokines during implantation and addresses novel and experimental therapies using platelet-rich plasma in fertility treatments. Our intent is to show a putative bridge between cytokines and growth factors produced by nucleated blood cells and the successful use of PRP in human-assisted reproduction. Computerized literature searches mainly using PubMed were performed for studies and reviews using the following terms alone or in combination: PRP, endometrium, implantation, gestation, growth factors, and blood-derived products. Additional relevant information was retrieved from the reference lists of a few articles.

\section{Growth factors, cytokines and implantation}

The term growth factor (GF) is used sometimes interchangeably with the term cytokine. Both represent signaling molecules that bind to specific receptors on the surface of their target cells, promoting cell proliferation, differentiation, maturation, or cell death. Growth factors usually are associated with positive cell signaling, whereas certain cytokines are associated with cell death as they may induce the target cell to undergo apoptosis.

These soluble proteins are produced by different cell types in many tissues, including reproductive and embryonic ones. The role played by cytokines and GFs in promoting endometrial receptivity has been reported in different studies over the last decades [10-13].
Cytokines are not a stable population of blood protein mediators. It has been demonstrated that cytokine measurement results vary according to factors, such as sample collection protocol, time of the day, fasting or food ingestion, exercise and stress, and arterial-venous blood sampling [14-16]. A key factor to be taken into account when cytokines are used on clinical therapies is the fact that cytokines have a short halflife, presenting rapid degradation in vitro after blood collection if appropriate storage and handling procedures are not employed [17]. For example, the half-life of TNF- $\alpha$ in plasma was calculated to be $18.30 \mathrm{~min}$ after release from PBMCs in vitro [18]. Aziz and colleagues [16] identified that handling and storage conditions before and during blood sample processing affected the stability of certain cytokines. Among the ones that easily become unstable under inappropriate handling conditions are interleukin-6 (IL-6) and tumor necrosis factor- $\alpha$ (TNF- $\alpha)$. The authors concluded that different cytokines present different stability depending on post-blood collection conditions.

Cytokines act in conjunction, and they may affect numerous target cells in a complex and highly regulated network, making it difficult to individualize the effect of each individual molecule. In humans, there is an increase of certain cytokines and GF mRNA profile around the time of implantation [19]. Despite the efforts to unveil all the molecules involved in implantation, the list is inexhaustible and continues to grow and the exact molecular mechanism underlying the phenomenon of implantation remains poorly understood [20].

Table 1 presents a summary of various growth factors known to be involved in the human implantation process.

\section{Blood-derived products and implantation}

Peripheral blood mononuclear cells (PBMCs) mainly consist of T- and B-lymphocytes and monocytes in mammalian species. In humans, PBMCs induce the production of several cytokines, such as IL-1 $\beta$ and TNF- $\alpha$, that play a key role in primary immune responses.

The idea of using autologous blood products to improve implantation and gestation is not new. More than three decades ago, the administration of a husband's lymphocytes to treat women suffering from spontaneous abortion of unknown etiology showed that this strategy allowed term gestation and birth of healthy babies in patients that developed immunological protective features to paternal alloantigens [34]. By that time, Wegmann [35] proposed the "immunotrophism hypothesis" after showing that T-cells are involved in placental growth and that they may help to prevent spontaneous miscarriage.

Subsequently, in vitro assays demonstrated that PBMCs derived from pregnant women increased progesterone production by luteal cells in culture. Also, the concentration of T- 
Table 1 Evidences of cytokine and growth factor involvement in human implantation

\begin{tabular}{|c|c|c|}
\hline Factor & Evidences & References \\
\hline$C S F-1$ & $\begin{array}{l}\text { CSF-1 is one of the signaling molecules found at the maternal-fetal interface during } \\
\text { the time of implantation }\end{array}$ & [21-23] \\
\hline$I L-6$ & $\begin{array}{l}\text { The expression of IL- } 6 \text { increases during the secretory/menstrual phases suggesting that } \\
\text { this cytokine may play a role in changes in endometrium that prepare it for im- } \\
\text { plantation and menstrual shedding. Abnormal expression of IL6 was reported dur- } \\
\text { ing mid-secretory (MS) phase in patients with recurrent abortions. }\end{array}$ & {$[10,19,24]$} \\
\hline$I L-8$ & $\begin{array}{l}\text { Interleukin- } 8 \text { (IL- } 8 \text { ) mRNA expression was shown to be the lowest during the prolif- } \\
\text { erative and early secretory phase. At the mid-secretory phase, an increased expres- } \\
\text { sion could be detected followed by the highest expression during the late secretory } \\
\text { pro-gestational phase. }\end{array}$ & {$[19]$} \\
\hline$L I F$ & $\begin{array}{l}\text { Leukemia inhibitory factor (LIF) mRNA and protein expression occurs throughout the } \\
\text { menstrual cycle, particularly in the middle- and late-secretory phases, when im- } \\
\text { plantation occurs. Mutations in the LIF gene occur in women with unexplained } \\
\text { infertility and repeated implantation failures. In addition, women with strong LIF } \\
\text { immunoreactivity during the window of implantation have greater probability of } \\
\text { getting pregnant in IVF cycles. }\end{array}$ & {$[25-27]$} \\
\hline$T G F-\beta$ & $\begin{array}{l}\text { During the menstrual cycle, the expression of the isoform transforming growth } \\
\text { factor-beta (TGF- } \beta \text { ) varies, being more intense in glandular epithelium during the } \\
\text { late-secretory phase. Moreover, TGF- } \beta \text { may play a role in human implantation by } \\
\text { promotion of adhesion of trophoblast cells to the ECM in in vitro assay. }\end{array}$ & {$[28]$} \\
\hline$T N F-\alpha$ & $\begin{array}{l}\text { Tumor necrosis factor-alfa (TNF- } \alpha \text { ) menstrual cycle-dependent expression in human } \\
\text { endometrium suggests that it has a role in menstrual bleeding and tissue shedding. } \\
\text { The progressive rise in TNF- } \alpha \text { endometrial tissue concentration during the } \\
\text { secretory/menstrual phase suggests that successful implantation and placentation } \\
\text { depend on a precise balance between the expression of TNF- } \alpha \text { and other cytokines } \\
\text { by immune and trophoblastic cells by the time implantation occurs. TNF- } \alpha \text { poly- } \\
\text { morphisms are associated with implantation rates in ART cycles. }\end{array}$ & $\begin{array}{l}{[10,11,29,} \\
30]\end{array}$ \\
\hline$V E G F$ & $\begin{array}{l}\text { Human endometrium expresses a secreted angiogenic growth factor whose site of } \\
\text { expression changes during the menstrual cycle. Vascular endothelial growth factor } \\
\text { (VEGF) levels are significantly reduced in uterine fluid during the MS phase in } \\
\text { women with unexplained infertility compared with fertile women. Culturing mouse } \\
\text { embryos with either MS-phase uterine fluid from fertile women or recombinant } \\
\text { human VEGF significantly enhanced blastocyst outgrowth. }\end{array}$ & {$[30-33]$} \\
\hline & VEGF polymorphisms are associated with implantation potential in ART cycles. & \\
\hline
\end{tabular}

helper 2-derived cytokines and interleukins IL-4 and IL-10 was increased in the co-culture of PBMCs and luteal cells derived from pregnant women [36]. The same authors also demonstrated that interleukins alone were proven to be as effective in stimulating corpus luteum progesterone production as hCG.

The effects of circulating PBMCs on embryo implantation were further investigated using the mouse model. The intravenous administration of spleen cells and thymocytes from pregnant and non-pregnant to pseudo-pregnant day 2 females induced earlier embryo implantation $[37,38]$. The role played by PBMCs on embryo invasion and implantation and hCG secretion was first observed using murine embryos and PBMCs obtained from women in early pregnancy [39]. Embryo invasiveness was significantly enhanced when they were exposed to PBMCs obtained from pregnant women. Furthermore, when PBMCs obtained from non-pregnant women were exposed to hCG for two days before the invasiveness assay, embryo invasion was similar to results obtained using PBMCs from pregnant women. However, embryo invasiveness was not affected by their exposure to $\mathrm{hCG}$ without the PBMCs. Subsequently, the role played by CD4(+)/CD25(+) regulatory T-cells in modulating immunetolerance at the implantation site was demonstrated in both mice and humans $[40,41]$. In another in vitro experiment that mimics the implantation window using human choriocarcinoma-derived BeWo cell mass and human endometrial epithelium, Kosaka and colleagues [42] showed that PBMCs promoted endothelial cell receptivity and increased attachment rates. In light of these findings, the "PBMC therapy" was proposed for patients with repeated implantation failures [43]. Blood samples were collected from each patient twice: at the day of oocyte retrieval and two days later. PBMCs isolated from the peripheral blood by the FicollHypaque method [36] were activated or not with HCG, pooled in a single-cell suspension, and administered into the uterine cavity to induce endometrial receptivity prior to blastocyst transfer [43]. The treatment was applied to 35 patients with four or more repeated implantation failures. Clinical pregnancy, implantation, and live birth rates were significantly increased in patients that received the autologous PBMC intrauterine administration [43]. Based on the evidences presented 
previously, Fujiwara [44] hypothesized that "circulating immune cells support the endocrine system to mediate embryomaternal cross-talk through systemic circulation". According to the author, maternal immune cells that have recognized the presence of an early embryo migrate to lymphoid organs to amplify the information and to mobilize other effector cells into systemic blood circulation to travel to the endometrium to induce tissue differentiation. Significantly improved pregnancy rates were also obtained when the "PBMC therapy" was applied in a bovine embryo transfer program in Japan [45]. Additional studies with cryopreserved human embryos showed that intrauterine administration of autologous PBMCs promoted increased implantation, clinical pregnancy rates, and live birth rates in RIF patients who underwent frozen/thawed embryo transfer cycles [46, 47]. It is also interesting to note that the study by $\mathrm{Li}$ and colleagues [47] also on frozen/thawed embryo transfer cycles pointed out that PBMC therapy was not effective on patients with one to three failed cycles, but pregnancy and live birth rates were significantly increased in patients with four or more implantation failures after frozen/thawed cleavage stage embryo transfer cycles.

\section{What is platelet-rich plasma?}

The concentrate of plasma platelets obtained by centrifugation of the patient's whole blood was named PRP. Platelets are nonnucleated cell fragments derived from megakaryocytes located in the bone marrow. Circulating anucleate platelets do not synthetize new proteins. All GFs and cytokines contained in cytoplasmic granules and delivered by platelets were produced by their mother cells, the megakaryocytes. The cytoplasm of platelets is divided in two regions: the chromomere, where granules accumulate, and the agranular hyalomere rich in cytoskeletal proteins. Platelet granules contain numerous proteins, several growth factors, and cytokines. When an injury or a cut occurs, platelets are "activated" and secrete these molecules that in turn act synergistically on local cells to promote wound healing by modifying the biological milieu to a suitable regenerative environment $[48,49]$.

The roles of platelets in homeostasis and preventing blood loss have been known for more than a century since they were first identified by Bizzozero in the 1880s [50]. More recently identified functions for platelets show that these cell fragments indeed participate in inflammatory processes and produce and release immunomodulatory factors [51-56], such as soluble CD40 ligand (CD154), which perform key roles in innate and adaptive immunity crosstalk. Thus, the administration of a platelet concentrate to a recipient represents also the infusion of a huge amount of cytokines and chemokines. Last but not least, reports describe the presence of antimicrobial peptides in platelet secretory granules [57].

Methods for preparing PRP have not been described in detail, and they vary considerably [58]. From the data available, it is difficult to know the precise cell composition present in PRP concentrates described in literature. It is also not possible to assess whether platelets underwent activation before or during the preparation process and if the secreted growth factors and cytokines were discarded together with the platelet-poor plasma (PPP). More importantly, there is neither knowledge of platelet count in a given preparation prior to use nor the dose that offers the best treatment effect.

Thus, preparation methods should be worldwide standardized to understand the putative mechanisms through which platelets or other cells present in peripheral blood are exerting their action on therapies of tissue regeneration and growth and to achieve consistent clinical outcomes.

The search for a repeatable and highly effective PRP preparation method led to the creation and optimization of protocols designed to maximize PRP regenerative and angiogenic properties $[59,60]$. The importance of a highly repeatable and efficient protocol to prepare platelets for clinical use is justified by the fact that the concentration of GFs and cytokines in a given preparation is related directly to the platelet count and proteins present in plasma [61].

Platelet preparations may be classified based on the presence of individual components [62]. The most common form of platelet concentrates is pure PRP and leukocyte PRP. Both are prepared by centrifugation of whole blood with anticoagulant and supplemented or not with platelet activators, such as $\mathrm{Ca}^{2+}$ or thrombin before administration. These preparations are liquid and therefore used as injections in contrast to the solid platelet preparation forms, such as platelet-rich fibrin [62]. Composition analysis of the PRP preparations revealed large variations in platelet and leukocyte counts.

The detailed in vitro study performed by Amable and colleagues [59] resulted in a consistent PRP preparation method. Peripheral blood was collected using tubes containing 3.2\% sodium citrate solution. The preparation protocol was divided into two centrifugation steps in which temperature, centrifugal force, and time were optimized. In the first centrifugation, the relative centrifugal force applied was $300 \times g$ for $5 \mathrm{~min}$ at $18^{\circ} \mathrm{C}$. The whole plasma above the buffy coat was collected (PRP1) and transferred to a new tube. The second centrifugation step used $700 \times g$ for $17 \mathrm{~min}$ at $18{ }^{\circ} \mathrm{C}$. The platelet-poor plasma (PPP) was transferred to a new tube. The platelet pellet obtained from $1 \mathrm{ml}$ of PRP1 was resuspended in $300 \mu \mathrm{l}$ of PPP (PRP2). Platelet activation was induced by adding $20 \mathrm{mM} \mathrm{CaCl}{ }_{2}$ and $25 \mathrm{IU} / \mathrm{ml}$ human thrombin incubated at $37{ }^{\circ} \mathrm{C}$ for $1 \mathrm{~h}$ or at $4{ }^{\circ} \mathrm{C}$ for $16 \mathrm{~h}$. Finally, for recovering the activated PRP2, samples were centrifuged at $3000 \times g$ for 20 min at $18{ }^{\circ} \mathrm{C}$ and the supernatant (activated PRP2) was collected by aspiration. The resulting platelet product, free from leukocytes and red blood cells, was proven to be rich in platelet-derived growth factor, endothelial growth factor, and transforming growth factor, together with antiinflammatory and pro-inflammatory interleukins, IL-4, IL-8, 
IL-13, IL-17, TNF- $\alpha$, and interferon (IFN)- $\alpha$. Additionally, the study characterized the GFs and cytokines derived from activated platelets and those present as a soluble in plasma.

\section{Platelet-rich plasma and endometrial receptivity}

As mentioned earlier, endometrial receptivity is a key factor for embryo implantation and gestation. Different approaches have been proposed along the years to improve endometrial receptivity in ART, including the above-mentioned intrauterine administration of autologous PBMCs and the more recent use of PRP.

After the pioneering work by Ferrari et al. [63] on the clinical application of autologous PRP in an open heart surgery to avoid excessive transfusion of homologous blood products, several others followed in different specialties of medical practice in the last decades.

The first report on the use of autologous PRP on fertility treatment was its intrauterine infusion on barren mares. The expression of inflammatory biomarkers of uterine biopsies obtained from mares susceptible to persistent matinginduced endometritis following intrauterine PRP infusion showed that mRNA expression of interleukins IL-1 $\beta$, IL-6, and IL-8 was significantly down-regulated $(P<0.05)$ when compared with untreated females [64]. Subsequently, a remarkable increase on gestational rates was reported in barren mares that received intrauterine PRP infusion before mating [65]. Reghini and colleagues [66] further confirmed these results showing that PRP intrauterine infusion is effective in modulating the exacerbated uterine inflammatory response to semen in mares with chronic degenerative endometritis. Another study using an in vitro cow model of endometrial inflammation showed that PRP-treated cells have an increased proliferation rate and higher expression of several genes involved in implantation [67]. The authors also demonstrated that progesterone receptor gene expression was higher in endometrial biopsies of cows treated with PRP infusion at day 4 post-estrus. These results prompted the authors to suggest a potential treatment of cow endometritis with PRP in vivo [67].

The putative involvement of platelets in the human implantation process was first put forward by Sato et al. [68]. The authors observed that platelets together with extravillous trophoblast cells replace endothelium and muscle layer, remodeling spiral arteries to become dilated. This contributes to an adequate blood supply into the intervillous space in the placenta.

Fujiwara [69] suggested that after the maternal immune system recognizes an embryo in the genital tract, the peripherally circulating immune cells act on reproductive organs to facilitate implantation. These observations were further extended to the proposal that circulating platelets are "novel regulators of neovascularization" and luteinization in the tissue remodeling process during corpus luteum (CL) formation [70].
This concept was subsequently extended to all peripheral blood cells [44]. Thus, all peripheral blood components, including platelets, would have a role in endometrial remodeling and embryo-maternal crosstalk at implantation time.

Endometrial growth has been the major reported effect after PRP intrauterine administration in patients presenting thin endometrium during ART cycles. Chang and colleagues [71] reported better endometrial growth and gestation outcomes after PRP infusion in patients with thin endometrium $(<$ $7 \mathrm{~mm}$ ). This first report was followed by others [72-74] showing an improvement on endometrial growth and fertility treatment outcome in patients with thin endometrium. Last, a case report described the successful pregnancy outcome of a patient diagnosed with recurrent implantation failure treated with autologous PRP intrauterine administration prior to embryo transfer [75]. Data presented on a recent report [72] suggests that PRP intrauterine infusion promotes neo-angiogenesis. The study shows that PRP administration in infertile women undergoing frozen embryo transfer cycles with suboptimal endometrium induced a significant increase in vascularity observed by the number of vascular signals seen on Power Doppler, reaching the zones 3 and 4 of the endometrium. Endometrial thickness along with chemical and clinical gestations rates significantly increased the post-PRP treatment in this group of patients. None of these reports, however, provide any evidence on which uterine cell type (epithelial, stromal, blood, vascular, or glandular cells) and the mechanism through which the blood preparation was being effective in improving receptivity and pregnancy.

One important point to be observed in the abovementioned reports is the fact that they do not describe in detail how PRP used for intrauterine administration was prepared from whole blood. Some of the descriptions barely even mention anything more than the "two-step" centrifugation, the buffy coat retrieval and administration in the uterine cavity as being the "PRP" treatment $[71,73,75,76]$. However, the buffy coat should contain leukocytes in addition to the platelets and plasma. As discussed before, leukocytes are also a source of several GFs and cytokines. Considering that the buffy coat may contain different amounts of leukocytes and plasma GFs, depending on how the blood sample was treated [59], it is difficult to ascertain which component of the final preparation is exerting its effect on endometrial receptivity, or as it may be more likely, which combination of factors found in the plasma preparation is promoting an improved endometrial environment for embryo implantation. The fact is though that none of the PRP studies describe an analysis of the cellular/acellular components of the plasma preparation prior to infusion. It is possible that the final PRP preparation employed in most reports contains white blood cells together with the platelets and they may be contributing with their cytokines and growth factors to the effects observed exerted by PRP samples. 
Furthermore, some authors used platelet activation components, such as calcium, while others do not mention the presence of any activating agent during plasma preparation. Platelet activation factors trigger the release of GFs and cytokines stored in platelet granules in plasma. Thus, these PRP preparations should be injected into uterine cavity immediately after being prepared, considering the short half-life of some of the cytokines and GFs.

Lastly, it must be taken into account that infertile patients presenting implantation failure are not all the same. Immunological and inflammatory factors should be investigated, and the possible presence of endometritis well documented before PRP treatment. To maximize PRP treatment effectiveness, patients should be discriminated according to their putative cause of implantation failure.

The first in vitro study designed to elucidate the cellular mechanisms involved in PRP endometrial regeneration presented evidence that activated PRP increased cell migration and proliferation in different in vitro cell types and enhanced expression of matrix proteins [77]. However, the study also showed that platelet-poor plasma (PPP) and non-activated PRP preparations were also effective at promoting cell migration and proliferation and increased gene expression of matrix proteins. These results may be due to the PRP/PPP preparation method, which may have segregated growth factors and cytokines present in the plasma fraction from those present in platelets or caused their release from the platelets upon activation or during preparation and storage in plasma before use.

\section{Conclusion}

In conclusion, we believe that it is possible to ascertain the therapeutic/regenerative role for platelet preparations. However, it is not possible at the moment to establish whether the therapeutic effects are exerted by the platelets alone or if they are the result of a combination of GFs and cytokines present in plasma or released by platelets and PBMCs upon blood collection and preparation. There seems to be no room for doubt on the important role played by the immune system cells and molecules underlying the effects of the different blood-derived product therapies. However, PRP treatment should be considered experimental and additional, concrete studies should be performed to address the immunological aspects of implantation before its use in clinical practice. On the other hand, because the patient is the source of the PRP preparation, the risk of contracting a blood-transmitted disease is avoided and the risk for an immune reaction is minimal [78].

Finally, considering that allogeneic blood transfusion is an established clinical practice, the creation of blood-derived product banks for regenerative therapies may not be a far reality, including endometrial receptivity improvement for ART patients.
Publisher's Note Springer Nature remains neutral with regard to jurisdictional claims in published maps and institutional affiliations.

\section{References}

1. Sharkey AM, Smith SK. The endometrium as a cause of implantation failure. Best Pract Res Clin Obstet Gynaecol. 2003;17:289307.

2. Carson DD, Bagchi I, Dey SK, Enders AC, Fazleabas AT, Lessey BA, et al. Embryo implantation. Devel Biol. 2000;223:217-37.

3. Duc-Goiran P, Mignot TM, Bourgeois C, Ferre F. Embryo-maternal interactions at the implantation site: a delicate equilibrium. Eur J Obstet Gynecol Reprod Biol. 1999;83:85-100.

4. Dey SK, Lim H, Das SK, Reese J, Paria BC, Daikoku T, et al. Molecular cues to implantation. Endocr Rev. 2004;25:341-73.

5. Check JH, Nowroozi K, Choe J, Lurie D, Dietterich C. The effect of endometrial thickness and echo pattern on in vitro fertilization outcome in donor oocyte-embryo transfer cycle. Fertil Steril. 1993;59(1):72-5.

6. Remohi J, Ardiles G, Garcia-Velasco JA. Endometrial thickness and serum oestradiol concentrations as predictors of outcome in oocyte donation. Hum Reprod. 1997;12:2271-6.

7. Zhao J, Zhang Q, Li Y. The effect of endometrial thickness and pattern measured by ultrasonography on pregnancy outcomes during IVF-ET cycles. Reprod Biol Endocrinol. 2012;28:100.

8. Quaas A, Dokras A. Diagnosis and treatment of unexplained infertility. Rev Obstet Gynecol. 2008;1:69-76.

9. Cicinelli E, Matteo M, Tinelli R, Lepera A, Alfonso R, Indraccolo $\mathrm{U}$, et al. Prevalence of chronic endometritis in repeated unexplained implantation failure and the IVF success rate after antibiotic therapy. Hum Reprod. 2015;30(2):323-30.

10. Tabibzadeh S, Babaknia A. The signals and molecular pathways involved in implantation, a symbiotic interaction between blastocyst and endometrium involving adhesion and tissue invasion. Hum Reprod. 1995; 10:1579-602.

11. Tabibzadeh S, Kong QF, Satyaswaroop PG, Babaknia A. Heat shock proteins in human endometrium throughout the menstrual cycle. Hum Reprod. 1996;11:633-40.

12. Tazuke SI, Giudice LC. Growth factors and cytokines in endometrium, embryonic development, and maternal:embryonic interactions. Semin Reprod Endocrinol. 1996;14:231-45.

13. Makrigiannakis A, Minas V, Kalantaridou SN, Nikas G, Chrousos GP. Hormonal and cytokine regulation of early implantation. Trends Endocrinol Metab. 2006;17:178-85.

14. Exley AR, Cohen J. Optimal collection of blood samples for the measurement of tumor necrosis factor alpha. Cytokine. 1990;2: 353-6.

15. Zhou X, Fragala MS, McElhaney JE, Kuchel GA. Conceptual and methodological issues relevant to cytokine and inflammatory marker measurements in clinical research. Curr Opin Clin Nutr Metab Care. 2010 Sep;13(5):541-7.

16. Aziz N, Detels R, Quint JJ, Li Q, Gjertson D, Butch AW. Stability of cytokines, chemokines and soluble activation markers in unprocessed blood stored under different conditions. Cytokine. 2016;84: 17-24.

17. Riches P, Gooding R, Millar BC, Rowbottom AW. Influence of collection and separation of blood samples on plasma IL-1, IL-6 and TNF-alpha concentrations. J Immunol Methods. 1992;153: 125-31.

18. Oliver JC, Bland LA, Oettinger CW, Arduino MJ, McAllister SK, Aguero SM, et al. Cytokine kinetics in an in vitro whole blood model following an endotoxin challenge. Lymphokine Cytokine Res. 1993;12(2):115-20. 
19. von Wolff M, Thaler CJ, Strowitzki T, Broome J, Stolz W, Tabibzadeh S. Regulated expression of cytokines in human endometrium throughout the menstrual cycle: dysregulation in habitual abortion. Mol Hum Reprod. 2000;6(7):627-34.

20. Raheem KA. Cytokines, growth factors and macromolecules as mediators of implantation in mammalian species. Int $\mathrm{J}$ Vet Sci Med. 2018;6:S6-S14.

21. Kauma SW, Aukerman SL, Eierman D, Turner T. Colony stimulating factor-1 and c-fms expression in human endometrial tissues and placenta during the menstrual cycle and early pregnancy. J Clin Endocr Metab. 1991;73:746-51.

22. Scarpellini F, Sbracia M. Use of granulocyte colony stimulating factor for the treatment of unexplained recurrent miscarriage: a randomized controlled trial. Hum Reprod. 2009;24:2703-8.

23. Gleicher N, Vidali A, Barad DH. Successful treatment of unresponsive thin endometrium. Fertil Steril. 2011;95(6): 2123):e13-7.

24. Lim KJ, Odukoya OA, Ajjan RA, Li TC, Weetman AP, Cooke ID. The role of T-helper cytokines in human reproduction. Fertil Steril. 2000:73136-42.

25. Serafini PC, Rocha AM, Osório CABT, Silva IDCG, Motta ELA, Baracat EC. Endometrial leukemia inhibitory factor as a marker of pregnancy after in vitro fertilization. Int $\mathrm{J}$ Gynaecol Obstet. 2008;102(1):23-7.

26. Arici A, Engin O, Attar E, Olive DL. Modulation of leukemia inhibitory factor gene expression and protein biosynthesis in human endometrium. J Clin Endocrinol Metab. 1995;80:1908-15.

27. Steck T, Ralf Giess R, Suetterlina MW, Bollanda M, Wiesta S, Poehlsa UG, et al. Leukaemia inhibitory factor (LIF) gene mutations in women with unexplained infertility and recurrent failure of implantation after IVF and embryo transfer. Eur J Obst Gynecol Reprod Biol. 2004;112:69-73.

28. Irving JA, Lala PK. Functional role of cell surface integrins on human trophoblast cell migration: regulation by TGF-beta, IGF-II, and IGFBP-1. Exp Cell Res. 1995;217(2):419-27.

29. Alijotas-Reig J, Esteve-Valverde E, Ferrer-Oliveras R, Llurba E, Gris JM. Tumor necrosis factor-alpha and pregnancy: focus on biologics. An updated and comprehensive review. Clin Rev Allergy Immunology. 2017;53:40-53.

30. Boudjenah R, Molina-Gomes D, Torre A, Boitrelle F, Taieb S, Santos E, et al. Associations between individual and combined polymorphisms of the TNF and VEGF genes and the embryo implantation rate in patients undergoing in vitro fertilization (IVF) programs. PLoS One. 2014;9(9):e108287.

31. Charnock-Jones DS, Sharkey AM, Rajput-Williams J, Burch D, Schofield JP, et al. Identification and localization of alternately spliced mRNAs for vascular endothelial growth factor in human uterus and estrogen regulation in endometrial carcinoma cell lines. Biol Reprod. 1993;48:1120-8.

32. Hannan NJ, Paiva P, Meehan KL, Rombauts LJF, Gardner DK, Salamonsen LA. Analysis of fertility-related soluble mediators in human uterine fluid identifies VEGF as a key regulator of embryo implantation. Endocrinology. 2011;152:4948-56.

33. Meduri G, Bausero P, Perrot-Applanat M. Expression of vascular endothelial growth factor receptors in the human endometrium: modulation during the menstrual cycle. Biol Reprod. 2000;62(2): 439-47.

34. Beer AE, Semprini AE, Zhu XY, Quebbeman JF. Pregnancy outcome in human couples with recurrent spontaneous abortions: HLA antigen profiles; HLA antigen sharing; female serum MLR blocking factors; and paternal leukocyte immunization. Exp Clin Immunogen. 1985;2(3):137-53.

35. Wegmann TG. Maternal T cells promote placental growth and prevent spontaneous abortion. Immunol Lett. 1988;17:297-302.

36. Hashii K, Fujiwara H, Yoshioka S, Kataoka N, Yamada S, Hirano T, et al. Peripheral blood mononuclear cells stimulate progesterone production by luteal cells derived from pregnant and non- pregnant women: possible involvement of interleukin-4 and interleukin-10 in corpus luteum function and differentiation. Hum Reprod. 1998;13(1O):2738-44.

37. Takabatake K, Fujiwara H, Goto Y, Nakayama T, Higuchi T, Maeda $\mathrm{M}$, et al. Intravenous administration of splenocytes in early pregnancy changes the implantation window in mice. Hum Reprod. 1997; 12:583-5.

38. Fujita K, Nakayama T, Takabatake K, Higuchi T, Fujita J, Maeda M, et al. Administration of thymocytes derived from non-pregnant mice induces an endometrial receptive stage and leukaemia inhibitory factor expression in the uterus. Hum Reprod. 1998;13:2888-94.

39. Nakayama T, Fujiwara H, Maeda M, Inoue T, Yoshioka S, Mori T, et al. Human peripheral blood mononuclear cells (PBMC) in early pregnancy promote embryo invasion in vitro: HCG enhances the effects of PBMC. Hum Reprod. 2002;17(1):207-12.

40. Aluvihare VR, Kallikourdis M, Betz AG. Regulatory T cells mediate maternal tolerance to the fetus. Nat Immunol. 2004;5:266-712.

41. Saito S, Shiozaki A, Sasaki Y, Nakashima A, Shima T, Ito M. Regulatory $\mathrm{T}$ cells and regulatory natural killer (NK) cells play important roles in feto-maternal tolerance. Semin Immunopathol. 2007;29:115-22.

42. Kosaka K, Fujiwara H, Tatsumi K, Yoshioka S, Higuchi T, Sato Y, et al. Human peripheral blood mononuclear cells enhance cell-cell interaction between human endometrial epithelial cells and BeWocell spheroids. Hum Reprod. 2003;18:19-25.

43. Yoshioka S, Fujiwara H, Nakayama T, Kosaka K, Mori T, Fujii S. Intrauterine administration of autologous peripheral blood mononuclear cells promotes implantation rates in patients with repeated failure of IVF-embryo transfer. Hum Reprod. 2006;21:3290-4.

44. Fujiwara H, Araki Y, Toshimori K. Is the zona pellucida an intrinsic source of signals activating maternal recognition of the developing mammalian embryo? J Reprod Immunol. 2009;81:1-8.

45. Ideta A, Sakai S, Nakamura Y, Urakawa M, Hayama K, Tsushiya $\mathrm{K}$, et al. Administration of peripheral blood mononuclear cells into the uterine horn to improve pregnancy rate following bovine embryo transfer. Anim Reprod Sci. 2010;117(1-2):18-23.

46. Okitsu O, Kiyokawa M, Oda T, Miyakea K, Sato Y, Fujiwara H. Intrauterine administration of autologous peripheral blood mononuclear cells increases clinical pregnancy rates in frozen/ thawed embryo transfer cycles of patients with repeated implantation failure. $\mathrm{J}$ Reprod Immunol. 2011;92:82-7.

47. Li S, Wang J, Cheng Y, Zhou D, Yin T, Xu W, et al. Intrauterine administration of hCG-activated autologous human peripheral blood mononuclear cells (PBMC) promotes live birth rates in frozen/thawed embryo transfer cycles of patients with repeated implantation failure. J Reprod Immunol. 2017;119:15-22.

48. Spaet TH, Stemerman MB. Platelet adhesion. Ann N Y Acad Sci. 1972;201:13-21.

49. Andia I, Maffulli N. Platelet-rich plasma for managing pain and inflammation in osteoarthritis. Nat Rev Rheumatol. 2013;9(12): 721-30.

50. Bizzozero G. Su di un nuovo elemento morfologico del sangue dei mammiferi e della sua importanza nella trombosi e nella coagulazione. LOsservatore. 1881;17:785-7.

51. Garraud O, Hamzeh-Cognasse H, Cognasse F. Platelets and cytokines: how and why? Transf Cliniq Biol. 2012;19:104-8.

52. Jenne CN, Urrutia R, Kubes P. Platelets: bridging hemostasis, inflammation, and immunity. Intern J Lab Hemat. 2013;35:254-61.

53. Ghoshal K, Bhattacharyya M. Overview of platelet physiology: its hemostatic and nonhemostatic role in disease pathogenesis. The Scient World J. 2014;2014: Article ID 781857:16.

54. Herter JM, Rossaint J, Zarbock A. Platelets in inflammation and immunity. J Thromb Haemost. 2014;12:1764-75.

55. Grozovsky R, Giannini S, Falet H, Hoffmeister KM. Regulating billions of blood platelets: glycans and beyond. Blood. 2015;126: $1877-84$. 
56. Thomas MR, Storey RF. The role of platelets in inflammation. Thrombos Haemostas. 2015;114:449-58.

57. Drago L, Bortolin M, Vassena C, Taschieri S, Del Fabbro M. Antimicrobial activity of pure platelet-rich plasma against microorganisms isolated from oral cavity. BMC Microbiol. 2013;13:47-51.

58. Bos-Mikich A, Oliveira R, Frantz N. Platelet-rich plasma therapy and reproductive medicine. J Assit Reprod Gent. 2018;35:753-6.

59. Amable PR, Teixeira MVT, Carias RBV, Granjeiro JM, Borojevic $R$. Identification of appropriate reference genes for human mesenchymal cells during expansion and differentiation. Stem Cell Res Ther. 2013;4:67.

60. Etulain J. Platelets in wound healing and regenerative medicine. Platelets. 2018;29(6):556-68.

61. Rubio-Azpeitia E, Bilbao AM, Sánchez P, Delgado D, Andia I. The properties of 3 different plasma formulations and their effects on tendinopathic cells. Am J Sports Med. 2016;44(8):1952-61.

62. Yung Y-L, Fu S-C, Cheuk Y-C, Qin L, Ong MT-Y, Chan K-M, et al. Optimisation of platelet concentrates therapy: composition, localisation, and duration of action. Asia-Pacific J Sports Med Arthrosc Rehabilit Technol. 2017;7:27e36.

63. Ferrari M, Zia S, Valbonesi M, Henriquet F, Venere G, Spagnolo S, et al. A new technique for hemodilution, preparation of autologous platelet-rich plasma and intraoperative blood salvage in cardiac surgery. Int J Artif Organs. 1987;10(1):47-50.

64. Metcalf ES, Scoggin K, Troedsson MHT. The effect of platelet-rich plasma on endometrial pro-inflammatory cytokines in susceptible mares following semen deposition (abstract). J Equine Vet Sci. 2012;32:498.

65. MetcalfES. The effect of platelet-rich plasma (PRP) on intraluminal fluid and pregnancy rates in mares susceptible to persistent matinginduced endometritis (PMIE). J Equine Vet Sci. 2014;34:128.

66. Reghini MFS, Neto CR, Segabinazzi LG, Chaves MBBC, Dell'Aqua CPF, Bussiere MCC, et al. Inflammatory response in chronic degenerative endometritis mares treated with platelet-rich plasma. Theriogenology. 2016;86:516-22.

67. Marini MG, Perrini C, Esposti P, Corradetti B, Bizzaro D, Riccaboni P, et al. Effects of platelet-rich plasma in a model of bovine endometrial inflammation in vitro. Reprod Biol Endocrinol. 2016;14:58-75.

68. Sato Y, Fujiwara H, Zeng B-X, Higuchi T, Yoshioka S, Fujii S. Platelet-derived soluble factors induce human extravillous trophoblast migration and differentiation: platelets are a possible regulator of trophoblast infiltration into maternal spiral arteries. Blood. 2005;106:428-35.

69. Fujiwara H. Hypothesis: immune cells contribute to systemic crosstalk between the embryo and mother during early pregnancy in cooperation with the endocrine system. Reprod Med Biol. 2006;5: 19-29.

70. Furukawa K, Fujiwara H, Sato Y, Zeng BX, Fujii H, Yoshioka S, et al. Platelet is a novel regulator for neovascularization and luteinization during human corpus luteum formation. Endocrinology. 2007;148:3056-64.

71. Chang Y, Li J, Chen Y, Wei L, Yang X, Shi Y, et al. Autologous platelet-rich plasma promotes endometrial growth and improves pregnancy outcome during in vitro fertilization. Int $\mathrm{J}$ Clin Exp Med. 2015;8:1286-90.

72. Tandulwadkar SR, Naralkar MV, Surana AD, Selvakarthick M, Kharat AH. Autologous intrauterine platelet-rich plasma instillation for suboptimal endometrium in frozen embryo transfer cycles: a pilot study. J Hum Reprod Sci. 2017;10(3):208-12.

73. Zadehmodarres S, Salehpour S, Saharkhiz N, Nazari L. Treatment of thin endometrium with autologous platelet-rich plasma: a pilot study. JBRA Assist Reprod. 2017;21(1):54-6.

74. Molina A, Sánchez J, Sánchez W, Vielma V. Platelet-rich plasma as an adjuvant in the endometrial preparation of patients with refractory endometrium. JBRA Assisted Reproduction. 2018;22(1):42-8.

75. Farimani M, Poorolajal J, Rabiee S, Bahmanzadeh M. Successful pregnancy and live birth after intrauterine administration of autologous platelet-rich plasma in a woman with recurrent implantation failure: a case report. Int J Reprod Biomed. 2017;15(12):803-6.

76. Nazari L, Salehpour S, Hoseini S, Zadehmodarres S, Ajori L. Effects of autologous platelet-rich plasma on implantation and pregnancy in repeated implantation failure: a pilot study. Int $\mathrm{J}$ Reprod Biomed (Yazd). 2016;14(10):625-8.

77. Aghajanova L, Houshdaran S, Balayan S, Manvelyan E, Irwin JC, Huddleston $\mathrm{HG}$, et al. In vitro evidence that platelet-rich plasma stimulates cellular processes involved in endometrial regeneration. J Assist Reprod Genet. 2018;35(5):757-70.

78. Marques LF, Stessuk T, Camargo IC, Sabeh Junior N, dos Santos L, Ribeiro Paes JT. Platelet rich plasma (PRP): methodological aspects and clinical applications. Platelets. 2015;26:101-13. 